\title{
Biosocial and disease conditions affecting the quality of life among older adults in Eastern Nepal
}

\section{Uday Narayan Yadav ( $\square$ unyadav1@gmail.com ) \\ Health Research and Social Development Forum https://orcid.org/0000-0002-6626-1604}

Tarka Bahadur Thapa

FHRD

\section{Sabuj Kanti Mistry}

BRAC University

\section{Saruna Ghimire}

Miami University

\section{Godfred O. Boateng}

University of Texas at Arlington College of Architecture Planning and Public Affairs

\section{Cathy O' Callaghan}

University of New South Wales

\section{Research article}

Keywords: Chronic diseases, older adults, quality of life, socio-demographic factors

Posted Date: January 8th, 2020

DOl: https://doi.org/10.21203/rs.2.20273/v1

License: (c) (i) This work is licensed under a Creative Commons Attribution 4.0 International License.

Read Full License 


\section{Abstract}

\section{Background}

The ageing population in most low-and middle-income countries is accompanied by an increased risk of non-communicable diseases culminating in a poor quality of life. However, the factors accelerating this poor quality of life (QOL) have not been fully examined. Therefore, this study examined the factors influencing the quality of life of Nepali older adults.

\section{Methods}

Data from a previous cross-sectional study, conducted between January and April 2018 in eastern Nepal, was used. The analytical sample included 794 older adults aged $\geq 60$ years, selected by a multi-stage cluster sampling approach. QOL was measured using the Older People's Quality of Life tool; dichotomized as poor and good QOL. Other measures used included age, gender, ethnicity, religion, marital status, physical activity and chronic diseases such as osteoarthritis, cardiovascular disease, diabetes, chronic obstructive pulmonary disease (COPD), and depression. The factors associated with quality of life were examined using mixed-effects logistic regression.

Results

Seven in ten respondents (70.4\%) reported a poor quality of life. At the bivariate level, increasing age, unemployment, intake of alcohol, lack of physical activity as well as osteoarthritis, COPD and depression were significantly associated with a lower likelihood of a good quality of life. The adjusted model showed that older age $(A O R=0.50, p<0.05)$, the Christian religion $(A O R=0.38, p<0.01)$, and being from an Indigenous, Dalit, or Madheshi background were associated with a lower likelihood of good quality of life. However, higher income of $>\mathrm{Nrs} 10,000$ (AOR=3.34, $p<0.001$ ), daily physical activity ( $A O R=3.33, p<0.001)$, and the absence of osteoarthritis and depression were associated with a higher odds ratio of good quality of life.

Conclusion

The findings of this study echo the need to develop and implement policies aimed at improving the sociocultural and disease conditions that catalyse poor quality of life in this population.

\section{Background}

Globally, the population of older adults aged above 60 years has seen an increase from 15\% in 2015 to an estimated prevalence of $22 \%$ in 2015 . The majority of these older populations currently live in low- and middle-income countries (LMICs) [1]. The demographic transition is evident in Nepal [2, 3], a South Asian Country between India and China. In 2011, approximately 2.5 million of the Nepalese population were 60 years and older [2]. The growth rate of the older population, at $3.5 \%$, has exceeded the growth rate of the general population at $1.35 \%$ [4]. 
Global aging has created a significant public health challenge for many countries, specifically LMICs, with scarce resources to address the social and health needs of its burgeoning population $[1,5]$. Generally, older adults are at a higher risk of developing non-communicable diseases, including cardiovascular diseases, diabetes, chronic kidney diseases, and mental health disorders [6, 7]. This also has implications for the functional capacity of the individuals culminating in deleterious consequences for the general well-being and QOL of this population [8, 9].According to the World Health Organization (WHO), QOL is the perceived position of an individual in the context of their value system and culture. It is also related to the goals, expectations, standards, and concerns of the individual's life [10]. Moreover, QOL is the result of the effect of physical, functional, social, and emotional factors that lead to individuals' wellness [11]. QOL has become an important outcome for many public health programs [12]. With an increase in the aging population, maintaining QOL of this elderly population has become an important challenge [13].

As a signatory of the sustainable development goals (SDG) for the 2030 agenda, the government of Nepal has formulated a national policy on ageing and recently "National Health Policy 2017" to address the needs of the Nepali older population. However, the implementations of the policy are limited to few programs such as "Old-Age-Allowance," "Jeshtha Nagarik Swashthopachar Kosh (Senior Citizens Health Facilities Fund)" and free "Health Care Service Program." However, the availability and quality of those services are questionable. Many older adults, especially in rural areas, are deprived of such benefits simply because they are not aware that such programs exist $[14,15]$, which may worsen their QOL relative to those benefiting from those programs. Previous studies on QOL among Nepalese elderly have been limited to the outpatient clinics [16] and nursing homes [17] in Nepal's capital city of Kathmandu. To achieve the SDG, it is important to identify the key factors influencing the health and QOL of the older population and operationalise appropriate policy mechanisms to improve the QOL of the elderly. Therefore, this current study aimed to 1) identify the state of QOL among Nepali older adults and 2) highlight the factors associated with QOL.

\section{Methodology}

\section{Study designs and participants}

Data from a previously conducted community-based cross-sectional study was used [18]. The study was conducted among older adults, aged $\geq 60$ years, living in the rural region of Morang and Sunsari districts of Nepal. The data collection took place between January-April 2018. The sample size of 847 was calculated based on following assumptions: prevalence of frailty $=50 \%$, sampling error $=5.0 \%, \mathrm{Cl}=95.0 \%$, design effect $=2$ and non-response rate $=5.0 \%$. A total of 794 eligible participants agreed to be interviewed using a survey method in the study resulting in a response rate of $93.7 \%$. Study participants were recruited from the community setting using a multi-stage cluster sampling approach. The detail on the sampling method has been fully described in our previously published work [18].

\section{Co-variates measurement}


We used semi-structured questionnaire to collect information on socio-demographic profiles, life-style behaviours and multi-morbidity history. Independent variables included were age; gender; ethnicity; religion; marital status; living arrangement; literacy status; occupation; monthly personal income; smoking habit; alcohol drinking habit; tobacco chewing habit; physical activity and presence of any co-morbidities. These co-variates are described in the published paper authored by Yadav et al. [19].

The English version of the questionnaire was first translated to Nepali and then translated (forwardbackward translation) back to English by two researchers to check the consistency of the instrument.

\section{Outcome variable}

QOL of the older adults was assessed by the Older People's Quality of Life (OPQOL) questionnaire [20], which is a novel instrument specifically designed to measure the QOL of older adults [21]. The OPQOL questionnaire has 35 questions that asked the participant to indicate the extent to which he/she agrees with each item in the Likert scale response (i.e., "strongly disagree", "disagree", "neither agree nor disagree", "agree" and "strongly agree"). Each of the five possible answers is scored between one ("strongly disagree") and five ("strongly agree"). The 35 items of this instrument consider the following aspects of QOL: life overall, health, social relationships and participation, independence, control over life and freedom, home and neighbourhood, psychological and emotional well-being, financial circumstances, leisure, activities, and religion. The cumulative score of the 35 items, which ranged from35 to 175, provides the measure of overall QOL; with higher scores indicating a better QOL. In this study, Cronbach's alpha for the OPQOL instrument was 0.75 , which indicates acceptable reliability of the tool.

\section{Ethics}

The study was approved by the Institutional Review Board of Nepal Health Research Council, Government of Nepal, Ministry of Health, Kathmandu. Prior to the interview, written informed consent was obtained from all literate participants, and thumb impressions were obtained from illiterate participants. Participants received an oral explanation about the study objectives, procedures and voluntary participation.

\section{Statistical analysis}

We employed descriptive, bivariate and multivariable regression models for this study. First, descriptive analysis was carried out to present the distribution of background characteristics. Frequency, percentage, mean, standard deviation (SD) and range distributions are presented. For the bivariate analysis, the chisquare $(X 2)$ test was performed to compare the percentage of participants with different QOL within different categories of variables at a $5 \%$ level of significance. Considering the nested nature of the survey data with possible variations among clusters (municipality), we performed a mixed-effect logistic regression model to assess the true association between the QOL and associated factors. Cluster variation was considered as a random effect and the rest of the variables were considered as fixed 
effects. The generalized estimating equation (GEE) was undertaken to estimate the parameters of the model while the exchangeable correlation structure within the clusters was employed. We retained in the final model only variables with a p-value of less than 0.25 in the bivariate model. Both unadjusted and adjusted odds ratios (ORs) are reported with $95 \%$ confidence intervals $(95 \% \mathrm{Cl})$. All analyses were performed using Stata v. 13.0 (Stata Corp, College Station, TX).

\section{Results}

\section{Descriptive statistics}

A total of 794 older adults aged 60 years and above participated in the study. The mean age of the participants was 69.9 years; more than half $(55.4 \%)$ were in their sixties (Table 1 ). The male to female ratio was close to unity ( $50.4 \%$ and $49.6 \%$, respectively). A greater proportion of the participants were Hindu (78.7\%) and illiterate (80.1\%). Nearly $38 \%$ of the participants were of indigenous origin, and $34 \%$ were from the Madhesi and other ethnic groups. About half of the participants (53.8\%) were married at the time of the survey. Regarding occupational status, $54.2 \%$ of the participants were not involved in any income-generating activities. As such, around half of the participants had a family income of 5000 NRs or less. More than three-quarters of the participants had no physical activity at all (77.1\%) and tobacco consumption history $(76.8 \%)$, while only a quarter $(25.1 \%)$ had alcohol drinking habits (Table 1$)$. Depression (55.8\%), osteoarthritis (41.7\%), and chronic obstructive pulmonary disease (COPD) (15.4\%) were the most prevalent health conditions among the participants (Table 2). 
Table 1

Relationship between socio-demographic, lifestyle characteristics and quality of life

\begin{tabular}{|c|c|c|c|c|c|c|c|}
\hline & \multicolumn{6}{|c|}{ Quality of life } & \multirow[b]{2}{*}{$\begin{array}{l}\mathrm{P} \\
\text { value }\end{array}$} \\
\hline & $\begin{array}{l}\text { Total }(\mathrm{N} \\
=794)\end{array}$ & $\%$ & $\begin{array}{l}\text { Poor } \\
(\mathrm{N}= \\
559)\end{array}$ & $\%$ & $\begin{array}{l}\text { Good } \\
(\mathrm{N}= \\
235)\end{array}$ & $\%$ & \\
\hline \multicolumn{8}{|l|}{ Age (year, \%) } \\
\hline $60-69$ & 440 & (55.42) & 293 & (66.59) & 147 & (33.41) & 0.009 \\
\hline $70-79$ & 235 & $(29.60)$ & 170 & $(72.34)$ & 65 & $(27.66)$ & \\
\hline$\geq 80$ & 119 & $(14.99)$ & 96 & $(80.67)$ & 23 & (19.33) & \\
\hline \multicolumn{8}{|l|}{ Gender } \\
\hline Male & 400 & $(50.38)$ & 249 & $(62.25)$ & 151 & $(37.75)$ & $\begin{array}{l}<.001 \\
0.001\end{array}$ \\
\hline Female & 394 & $(49.62)$ & 310 & (78.68) & 84 & $(21.32)$ & \\
\hline \multicolumn{8}{|l|}{ District } \\
\hline Morang & 404 & $(50.88)$ & 226 & $(55.94)$ & 178 & $(44.06)$ & $\begin{array}{l}<.001 \\
0.00\end{array}$ \\
\hline Sunsari & 390 & $(49.12)$ & 333 & (85.38) & 57 & $(14.62)$ & \\
\hline \multicolumn{8}{|l|}{ Religion } \\
\hline Hinduism & 625 & $(78.72)$ & 437 & $(69.92)$ & 188 & $(30.08)$ & $\begin{array}{l}< \\
0.001\end{array}$ \\
\hline Buddhism & 19 & $(2.39)$ & 4 & $(21.05)$ & 15 & (78.95) & \\
\hline Islam & 125 & $(15.74)$ & 104 & $(83.20)$ & 21 & $(16.80)$ & \\
\hline Christianity & 25 & $(3.15)$ & 14 & $\begin{array}{l}(56 . \\
00)\end{array}$ & 11 & $\begin{array}{l}(44 . \\
00)\end{array}$ & \\
\hline \multicolumn{8}{|l|}{ Ethnicity } \\
\hline Brahmin/Chettri/Thakuri & 69 & $(8.69)$ & 29 & (42.03) & 40 & (57.97) & \\
\hline Indigenous & 298 & (37.53) & 186 & $(62.42)$ & 112 & (37.58) & $\begin{array}{l}<.001 \\
0.00\end{array}$ \\
\hline Dalit & 157 & (19.77) & 119 & $(75.80)$ & 38 & $(24.20)$ & \\
\hline $\begin{array}{l}\text { Madhesi and other } \\
\text { ethnic groups }\end{array}$ & 270 & (34.01) & 225 & (83.33) & 45 & (16.67) & \\
\hline
\end{tabular}

${ }^{1}$ Others denotes widow/widower/divorced/separated/unmarried. 


\section{Quality of life}

Marital status

$\begin{array}{llllllll}\text { Married } & 425 & (53.53) & 274 & (64.48) & 151 & (35.53) & <.001 \\ & & & & & & & 0.001 \\ { }^{1} \text { Others } & 369 & (46.47) & 285 & (77.24) & 84 & (22.76) & \end{array}$

Literacy

$\begin{array}{lccccccc}\text { Illiterate } & 636 & (80.10) & 471 & (74.06) & 165 & (25.94) & < \\ & & & & & & & 0.001 \\ \text { literate } & 158 & (19.90) & 88 & (55.70) & 70 & (44.30) & \end{array}$

Past occupation

$\begin{array}{lccccccc}\text { Employed } & 364 & (45.84) & 210 & (57.69) & 154 & (42.31) & <.001 \\ \text { Unemployed } & 430 & (54.16) & 349 & (81.16) & 81 & (18.84) & \end{array}$

Family monthly income

$\begin{array}{llllllll}\text { Nrs. }<=5000 & 381 & (47.98) & 312 & (81.89) & 69 & (18.11) & <.001 \\ \text { Nrs. } 5000<=10000 & 145 & (18.26) & 94 & (64.83) & 51 & (35.17) & \\ \text { Nrs. }>10000 & 268 & (33.75) & 153 & (57.09) & 115 & (42.91) & \end{array}$

Tobacco using habit

$\begin{array}{llllllll}\text { Never tobacco user } & 184 & (23.17) & 134 & (72.83) & 50 & (27.17) & 0.187 \\ \begin{array}{l}\text { Having tobacco use } \\ \text { history }\end{array} & 610 & (76.83) & 425 & (69.67) & 185 & (30.33) & \end{array}$

Alcohol drinking habit

$\begin{array}{llllllll}\text { Never drinker } & 504 & (63.48) & 369 & (73.21) & 135 & (26.79) & 0.022 \\ \begin{array}{l}\text { Having alcohol drinking } \\ \text { history }\end{array} & 290 & (36.52) & 190 & (65.52) & 100 & (34.48) & \end{array}$

Physical activity

\begin{tabular}{|c|c|c|c|c|c|c|c|}
\hline $\begin{array}{l}\text { No physical exercise at } \\
\text { all }\end{array}$ & 612 & (77.08) & 500 & $(81.70)$ & 112 & (18.30) & 0.003 \\
\hline Daily physical exercise & 182 & (22.92) & 59 & (32.42) & 123 & $(67.58)$ & \\
\hline
\end{tabular}

${ }^{1}$ Others denotes widow/widower/divorced/separated/unmarried. 
Table 2

Relationship between chronic disease condition and QOL

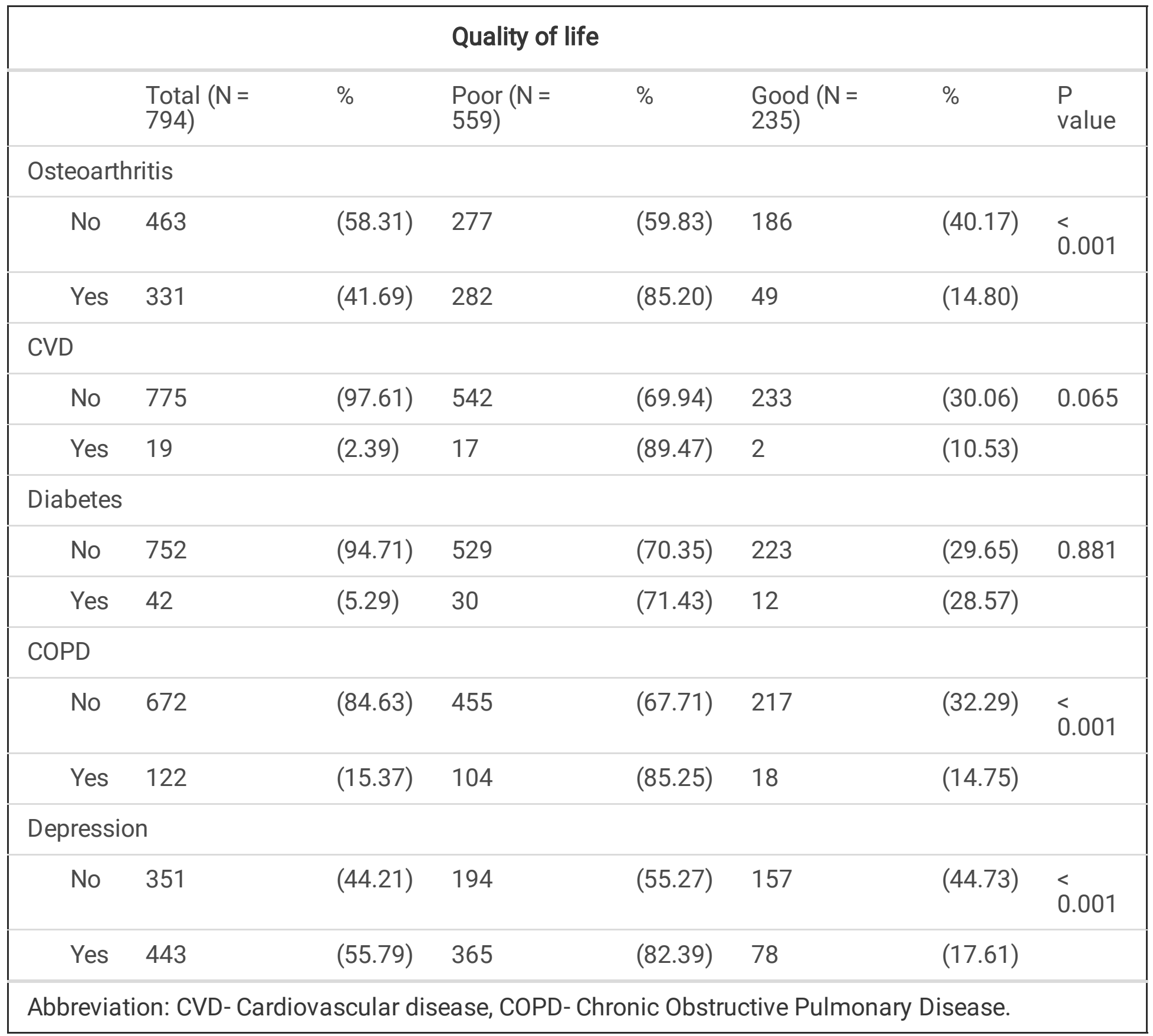

\section{Distribution of socioeconomic and lifestyle characteristic with QOL}

Based on our classification, about two-thirds (70.4\%) of our respondents reported poor QOL. The relationship between socio-demographic, lifestyle characteristics and QOL are summarized in Table 1. The proportion of participants reporting a poor QOL was significantly higher among those aged $\geq$ 80 years ( $p$-value $=0.009)$, female ( $p$-value $<0.001$ ), living in Sunsari district ( $p$-value $<0.001)$, following Hinduism ( $p$-value $<0.001$ ), from Brahmin/Chettri/Thakur ethnicity ( $p$-value $<0.001$ ), unmarried ( $p$-value $<$ 0.001 ), illiterate ( $p$-value $<0.001)$, unemployed ( $p$-value $<0.001)$, earned $\leq 5000 \mathrm{Nrs}$. $/$ month ( $p$-value $=$ $0.000)$ and had no physical activity at all ( $p$-value $=0.003)($ Table 1$)$.

Chronic condition and QOL 
The Chi-square test for the relationship between chronic conditions and QOL showed that participants with prevalent osteoarthritis ( $p$-value $<0.001)$, COPD ( $p$-value $<0.001)$, and depression ( $p$-value $<0.001)$ had significantly poor QOL (Table 2).

\section{Summary of QOL indices}

The numeric indices of QOL scores by different domains are presented in Table 3. The highest mean scores were in the religion/culture and independence domains with a score of 90.15 (16.39) and 72.66 (15.01), respectively. On the contrary, health 46.22 (17.47) and psychological 46.34 (15.52) domains had the lowest mean scores among this population.

Table 3

Summary measures for different domains of quality of life

\begin{tabular}{|lllll|}
\hline Domains & Mean & SD & Min & Max \\
\hline Life overall & 61.61 & 17.42 & 20.00 & 100.00 \\
\hline Health & 46.22 & 17.47 & 20.00 & 100.00 \\
\hline Social relationships & 68.36 & 11.91 & 20.00 & 97.50 \\
\hline Independence & 72.66 & 15.01 & 20.00 & 100.00 \\
\hline Home and neighbourhood & 65.40 & 15.40 & 20.00 & 100.00 \\
\hline Psychological & 46.34 & 15.52 & 20.00 & 100.00 \\
\hline Financial & 69.43 & 13.64 & 20.00 & 100.00 \\
\hline Religion/culture & 90.15 & 16.39 & 20.00 & 100.00 \\
\hline Overall & 112.32 & 16.61 & 64.00 & 159.00 \\
\hline Abbreviation: SD- standard deviation & & & \\
\hline
\end{tabular}

\section{Association of risk factors with QOL}

The multiple logistic regression model to assess the determinants of QOL is presented in Table 4. In the final model, age, religion, ethnicity, literacy, income, physical exercise, osteoarthritis, and depression were significantly associated with good QOL. An individual aged $70-79$ years and $\geq 80$ years had $34 \%$ [Adjusted Odds Ratio (AOR): 0.65; 95\% Confidence Interval (Cl): 0.49-0.88; p-value $=0.005$ ] and 50\% (AOR: $0.50 ; 95 \% \mathrm{Cl}$ : $0.28-0.90 ; p$-value $=0.021$ ) lower odds of having good QOL respectively compared to than individual aged 60-69 years. Compared to a participant of Hindu religion, higher odds of having good QOL was found in a Buddhist participant (AOR: 3.08; 95\% Cl: 2.32-4.11; p-value =0.000); at the same time lower odds were seen among Christian participants (AOR: 0.38; 95\% Cl: 0.20-0.70; $p$-value = 0.002). Participants from Indigenous, Dalit and Madhesi/other ethnic groups had $75 \%$ (AOR: $0.25 ; 95 \% \mathrm{Cl}$ : $0.14-0.47$; p-value $=0.000$ ), 77\% (AOR: $0.23 ; 95 \% \mathrm{Cl}: 0.10-0.56$; $p$-value $=0.001$ ) and 71\% (AOR: 0.29; $95 \% \mathrm{Cl}: 0.14-0.60 ; p$-value $=0.001)$ lower odds of having good QOL respectively compared to Brahmin/Chettri/Thakur. 
Table 4

Multiple logistic regression model of the determinants of QOL

\begin{tabular}{|c|c|c|c|c|c|c|}
\hline & \multicolumn{3}{|c|}{ Crude } & \multicolumn{3}{|c|}{ Adjusted $^{a}$} \\
\hline & OR & $\begin{array}{l}\mathrm{P}- \\
\text { value }\end{array}$ & $95 \% \mathrm{Cl}$ & OR & $\begin{array}{l}\mathrm{P}- \\
\text { value }\end{array}$ & $95 \% \mathrm{Cl}$ \\
\hline \multicolumn{7}{|l|}{ Age (year, \%) } \\
\hline $60-69$ & 1.00 & & & 1.00 & & \\
\hline $70-79$ & 0.75 & 0.020 & $\begin{array}{l}0.59- \\
0.96\end{array}$ & 0.65 & 0.005 & $0.49-0.88$ \\
\hline$>=80$ & 0.47 & 0.011 & $\begin{array}{l}0.26- \\
0.84\end{array}$ & 0.50 & 0.021 & $0.28-0.90$ \\
\hline \multicolumn{7}{|l|}{ Gender } \\
\hline Male & 1.00 & & & & & \\
\hline Female & 0.55 & 0.010 & $\begin{array}{l}0.35- \\
0.87\end{array}$ & 0.78 & 0.279 & $0.49-1.21$ \\
\hline \multicolumn{7}{|l|}{ District } \\
\hline Morang & 1.00 & & & 1.00 & & \\
\hline Sunsari & 0.21 & 0.002 & $\begin{array}{l}0.08- \\
0.57\end{array}$ & 0.57 & 0.133 & $0.27-1.19$ \\
\hline \multicolumn{7}{|l|}{ Religion } \\
\hline Hinduism & 1.00 & & & 1.00 & & \\
\hline Buddhism & 1.70 & $<.001$ & $\begin{array}{l}1.43- \\
2.02\end{array}$ & 3.08 & $<.001$ & $2.32-4.11$ \\
\hline Islam & 0.75 & 0.211 & $\begin{array}{l}0.48- \\
1.18\end{array}$ & 0.97 & 0.912 & $0.57-1.65$ \\
\hline Christianity & 0.59 & 0.049 & $\begin{array}{l}0.34- \\
0.99\end{array}$ & 0.38 & 0.002 & $0.20-0.70$ \\
\hline \multicolumn{7}{|l|}{ Ethnicity } \\
\hline Brahmin/Chettri/Thakuri & 1.00 & & & 1.00 & & \\
\hline Indigenous & 0.28 & $<.001$ & $\begin{array}{l}0.13- \\
0.59\end{array}$ & 0.25 & $<.001$ & $0.14-0.47$ \\
\hline
\end{tabular}

Significant $\mathrm{p}$-values are bolded. ${ }^{2}$ Others denotes widow/widower/divorced/separated/unmarried. ${ }^{2} 100$ Nrs approximates 1 US Dollar. Abbreviation: CVD- Cardiovascular disease, COPD- Chronic Obstructive Pulmonary Disease. 


\begin{tabular}{|c|c|c|c|c|c|c|}
\hline \multirow[b]{2}{*}{ Dalit } & \multicolumn{3}{|c|}{ Crude } & \multicolumn{3}{|c|}{ Adjusted $^{\mathrm{a}}$} \\
\hline & 0.22 & $<.001$ & $\begin{array}{l}0.10- \\
0.50\end{array}$ & 0.23 & 0.001 & $0.10-0.56$ \\
\hline $\begin{array}{l}\text { Madheshi and other ethnic } \\
\text { groups }\end{array}$ & 0.28 & $<.001$ & $\begin{array}{l}0.16- \\
0.49\end{array}$ & 0.29 & 0.001 & $0.14-0.60$ \\
\hline \multicolumn{7}{|l|}{ Marital status } \\
\hline Married & \multicolumn{3}{|l|}{1.00} & \multicolumn{3}{|l|}{1.00} \\
\hline${ }^{1}$ Others & 0.75 & 0.198 & $\begin{array}{l}0.49- \\
1.16\end{array}$ & 1.30 & 0.370 & $0.73-2.33$ \\
\hline \multicolumn{7}{|l|}{ Literacy } \\
\hline Illiterate & \multicolumn{3}{|l|}{1.00} & \multicolumn{3}{|l|}{1.00} \\
\hline literate & 3.22 & $<.001$ & $\begin{array}{l}2.08- \\
4.50\end{array}$ & 3.41 & $<.001$ & $2.52-4.60$ \\
\hline \multicolumn{7}{|l|}{ Occupation } \\
\hline Unemployed & \multicolumn{3}{|l|}{1.00} & \multicolumn{3}{|l|}{1.00} \\
\hline Employed & 0.58 & 0.002 & $\begin{array}{l}0.41- \\
0.82\end{array}$ & 0.71 & 0.194 & $0.42-1.19$ \\
\hline \multicolumn{7}{|l|}{${ }^{2}$ Income } \\
\hline Nrs. $<=5,000$ & \multicolumn{3}{|l|}{1.00} & \multicolumn{3}{|l|}{1.00} \\
\hline Nrs. $5,000<=10,000$ & 2.01 & 0.014 & $\begin{array}{l}1.15- \\
3.51\end{array}$ & 3.02 & 0.002 & $1.51-6.07$ \\
\hline Nrs. $>10,000$ & 1.72 & 0.005 & $\begin{array}{l}1.18- \\
2.51\end{array}$ & 3.34 & 0.001 & $1.43-3.99$ \\
\hline \multicolumn{7}{|l|}{ Tobacco using habit } \\
\hline Never tobacco user & \multicolumn{3}{|l|}{1.00} & \multicolumn{3}{|c|}{ Not taken in the model } \\
\hline Having tobacco use history & 0.96 & 0.636 & $\begin{array}{l}0.64- \\
1.44\end{array}$ & & & \\
\hline \multicolumn{7}{|l|}{ Alcohol drinking habit } \\
\hline Never drinker & \multicolumn{3}{|l|}{1.00} & \multicolumn{3}{|c|}{ Not taken in the model } \\
\hline Having alcohol drinking history & 1.06 & 0.759 & $\begin{array}{l}0.72- \\
1.58\end{array}$ & & & \\
\hline $\begin{array}{l}\text { Significant p-values are bolded. }{ }^{2} \text { Oth } \\
2100 \text { Nrs approximates } 1 \text { US Dollar. } \\
\text { Obstructive Pulmonary Disease. }\end{array}$ & $\begin{array}{l}\text { denote } \\
\text { reviati }\end{array}$ & $\begin{array}{l}\text { widow } \\
\text { n: CVD- }\end{array}$ & $\begin{array}{l}\text { idower/ } \\
\text { rdiovas }\end{array}$ & $\begin{array}{l}\text { dised/se } \\
\text { diseas }\end{array}$ & $\begin{array}{c}\text { arated/ } \\
\text { COPD- }\end{array}$ & $\begin{array}{l}\text { narried. } \\
\text { ronic }\end{array}$ \\
\hline
\end{tabular}


Crude

Physical activity

No physical exercise at all

Daily physical exercise
1.00

4.54
$<$

0.001
1.00

$2.17 \quad 0.011$
Adjusted $^{a}$

\section{Osteoarthritis}

Yes

No

CVD

Yes

1.00

2.54

0.133

$0.75-$

8.54

1.00

3.33

$<$

0.001
$2.55-4.34$

$2.55-4.34$

No

Diabetes

Yes

1.00

$1.20-$

3.93

1.00

$\begin{array}{lll}1.95 & 0.025 & 1.09-3.49\end{array}$

No

1.15

0.745

2.50

COPD

Yes

1.00

1.00

No

1.88

$\begin{array}{ll}<.001 & 1.32- \\ 0.008\end{array}$

1.19

0.665

$0.54-2.59$

Depression

Yes

1.00

1.00

No

3.15

$<$

$1.69-$

0.001

5.88

3.34

$<$

0.001

$2.14-5.22$

10.72

Significant p-values are bolded. ${ }^{2}$ Others denotes widow/widower/divorced/separated/unmarried. 2100 Nrs approximates 1 US Dollar. Abbreviation: CVD- Cardiovascular disease, COPD- Chronic Obstructive Pulmonary Disease.

A literate elderly individual had almost three times higher odds of leading good QOL compared to an illiterate individual (AOR:3.41; 95\% Cl: 2.52-4.60; p-value $=0.000$ ). The log-likelihood of good QOL also increased with increasing income. An elderly Nepalese with a family monthly earning of $\mathrm{Nrs} .5,000<=$ 10,000 and Nrs. > 10,000 had almost three times (AOR: 3.02; 95\% Cl: 1.51-6.07; p-value $=0.002$ ) and three and a half times (AOR: 3.34; 95\% Cl: $1.43-3.99 ; \mathrm{p}$-value $=0.001$ ) higher odds to lead a good QOL 
compared to those who earned Nrs. $<=5,000$. Good QOL was also associated with being physically active (AOR: 3.33; 95\% Cl: 2.55-4.34; p-value = 0.000), having no osteoarthritis (AOR: 1.9; 95\% Cl: 1.09-3.49; pvalue $=0.025 ;$ compared to having osteoarthritis) and no depression (AOR: 3.34; 95\% Cl: 2.14-5.22; pvalue $=0.000$; compared to having depression) .

\section{Discussion}

This study aimed to assess the QOL and its correlates among older adults in Eastern Nepal and found that seven in ten participants had poor QOL, which was significantly associated with age, socioeconomic status, religion, ethnicity, physical activity, osteoarthritis, and depression.

The overall poor QOL observed in this study is consistent with previous studies from Nepal's capital city of Kathmandu, where older patients in an outpatient clinic [16] and nursing homes [17] settings, had a lower overall QOL score. Previous studies, from international settings, are in line with our findings [22, 23]. Further, a gradient decline in the odds of poor QOL was noted by increasing age group which is in line with a previous study from Nepal where age was inversely associated with QOL [24]. The declining QOL with age is plausible, given that older adults are at increased risk of chronic diseases and infection [6, 25]. Furthermore, age is associated with a progressive decline in muscle mass, strength, power, and physical performance $[8,9]$. As a result, they have reduced mobility and functional capacity which ultimately influences the overall wellbeing and lowers the QOL at later life $[8,9]$.

A significant finding of this study is the role of socioeconomic status and its implications for QoL. Better socioeconomic status, as indicated by literacy and higher income in this study, was associated with higher QOL among older adults in our study as well as others [26-28]. Socioeconomic status is considered as one of the driving forces for the existing health disparities globally [29]. Given the wellestablished relationship between socio-economic status and well-being, in terms of perceived health [30], mortality, and morbidity [31, 32], the observed association with QOL was anticipated. Education increases health literacy and influences one's ability to make informed decisions about their health and healthy behaviours [33]. Likewise, income increases purchasing capacity, access to health care, and affordability of everyday need [34]. Together, education and income may determine one's social status and the psychosocial advantages gained through social networks [34]. Specifically, among the older adults from the life-course approach to aging, the better SES may reflect the relative advantages, in terms of better economic and social positions, accumulated over the life course that may lead to better QOL in later life [35].

Similar to prior studies[36, 37], physical activity among the elderly was associated with QOL. The role of physical activity in the reduction of risk of chronic diseases and premature mortality, as well as the promotion of physical functionality and health in the general population, is well established [38-40]. However, within the confines of this population, it provides evidence for the continual effect of physical activity over the life course. The pathways linking physical activity with QOL may be through the prevention of chronic diseases and the promotion of physical functioning and overall well-being. 
Previously, among older adults, several mediators such as better physical and mental health status increased exercise self-efficacy, increased physical self-worth, and reduced disability limitations, has been identified in the pathways between increased physical activity and QOL [36, 37].

In the context of Nepal, an individual's ethnicity has similar effects as their socio-economic status. Hence, it is not surprising to find that ethnicity was associated with QOL. Thus, compared to

Brahmin/Chettri/Thakur, which is considered as the upper caste, participant's from Indigenous, Dalit, and Madhesi/other ethnic groups had $75 \%, 77 \%$, and $71 \%$ lower odds of having good QOL respectively. This is consistent with previous studies from Nepal, which have also suggested lower QOL scores among Dalits than the upper castes, although the findings were statistically non-significant [16, 24]. Likewise, our finding aligns with the established notion that the Madhesi, Dalits, and Indigenous, being one of the marginalised groups, have poor outcomes in health and wellbeing, and socioeconomic status [41, 42]. Historically, these ethnic groups were considered disadvantaged in the society, in terms of their access to education and employment, and were discriminated against by the upper caste groups. Although, in recent years, such discrimination against them is criminalised by the law and many organisations are in place to uplift their social mobility, the quest for equality is still a long journey, especially in rural parts where illiteracy is high and traditions are deep-rooted [4]. This finding may suggest that the ethnic group you are born into may determine your QOL.

Another significant finding made from this study is the significant association between religiosity and QOL. Here, compared to a Hindu participant, QOL was higher among Buddhist participants and lower among Christian participants. Although the underlying explanations for the observed differences in QOL by religion are unknown, the literature does suggest that spirituality and religiosity are important components of QOL at any age [43]. Religious involvement may buffer stress and increase happiness, meaning, purpose, hope in life, which ultimately leads to better QOL [44]. Future studies have the opportunity to delve more on the observed association between religion and QOL; specifically, qualitative studies may be helpful to explore minority participant's perceptions.

Physical and mental ailments were associated with lower QOL. Absence of osteoarthritis and depression was associated with higher odds of better QOL. Previously, low perceived QOL among patients with osteoarthritis is reported $[45,46]$. The pain and limitations of daily living activities resulting from osteoarthritis may explain the observed reduced QOL $[46,47]$.

Our findings of an inverse association between QOL and depression are consistent with previous studies from Nepal and globally $[23,48,49]$. A meta-analysis of 24 studies reported moderate improvements in QOL following treatments for depression [50]. Depression may lower the QOL by impairing physical and social functioning, and overall health [51].

\section{Strengths And Limitations}

As with most studies, this study has some limitations. The participants were from eight rural municipalities of Morang and Sunsari district, Nepal; thus, the results can be only generalized to the 
studied setting. Secondly, social- desirability bias may have occurred as our findings relied on selfreported data. Further, the study adopted a cross-sectional design, which precludes any inferences of the cause-effect relationships. The most important strength of this study includes a large sample size with more than $90 \%$ response rate, strong methodology, and adoption of Older People's Quality of Life (OPQOL) questionnaire for the first time in Nepalese settings.

\section{Conclusion}

This study has provided statistical evidence of the factors influencing the good QOL among the elderly in Nepal. The current study shows that one in three respondents have a good QOL. In delineating the mechanism by which this happens, the results demonstrate that biosocial factors such as increasing age and ethnicity outside the upper caste decrease the likelihood of a good QOL. Similarly, disease conditions such as depression and COPD were found to be associated with a lower likelihood of a good QOL. However, compositional factors such as literacy and high-income levels were found to increase the likelihood of a good QOL. These results provide compelling evidence to develop and implement policies aimed at improving the conditions that catalyse poor QOL in this population.

\section{Abbreviations}

aOR: Adjusted Odds Ration; Cl: Confidence Interval; QOL: Quality of Life; Older People's Quality of Life (OPQOL); LMICs: Low- and middle-income countries (LMICs; WHO: World Health Organisation; SDG: Sustainable Development Goals

\section{Declarations}

\section{Acknowledgements}

We would like to thank all the participants of this study and local government bodies. Authors acknowledge the assistance of Prof. Renuka Viswanathan (Director, Aged \& Extended Care Service, University of Adelaide) for her technical inputs in this project.

\section{Author's contribution}

Conceived and designed the study: UNY and TBT. Performed field work: UNY and TBT, Analysed data: UNY, SKM, SG, COC and GOB. Initial draft preparation: UNY, TBT, SKM, SG, COC and GOB. All authors read and approved the final manuscript.

\section{Funding}

The UNY received funding from Nepal Health Research Council, Ministry of Health, Government of Nepal (Provincial grant). The funders had no role in the study design, data collection and analysis of the data.

\section{Availability of data and materials}


The datasets used and/or analyzed during the current study are available from the corresponding author on reasonable request.

Ethics approval and consent to participate

The study was approved by the Institutional Review Board of Nepal Health Research Council, Government of Nepal, Ministry of Health, Kathmandu. After detailed information, all study participants gave their written informed consent.

Consent for publication

Not applicable.

Competing interests

The authors declare that they have no competing interests.

\section{References}

1. WHO and US National Institute of Aging: Global health and ageing. In. Edited by Aging WUNIo; 2011.

2. Shrestha L: Geriatric health in Nepal: concerns and experience. Nepal Med Coll J 2013, 15(2):148152.

3. Commission NP: Demographic Changes of Nepal: Trends and Policy Implications. Kathmandu: National Planning Commission, Government of Nepal; 2017. In.

4. Central Bureau of Statistics: National Population and Housing Census 2011. Kathmandu, Nepal 2012.

5. Kowal P, Kahn K, Ng N, Naidoo N, Abdullah S, Bawah A, Binka F, Chuc NT, Debpuur C, Ezeh A et al: Ageing and adult health status in eight lower-income countries: the INDEPTH WHO-SAGE collaboration. Glob Health Action 2010, 3.

6. Arokiasamy P, Uttamacharya, Kowal P, Capistrant BD, Gildner TE, Thiele E, Biritwum RB, Yawson AE, Mensah G, Maximova T et al: Chronic Noncommunicable Diseases in 6 Low- and Middle-Income Countries: Findings From Wave 1 of the World Health Organization's Study on Global Ageing and Adult Health (SAGE). Am J Epidemiol 2017, 185(6):414-428.

7. WHO: Mental health of older adults. In.; 2017.

8. Visser M, Goodpaster BH, Kritchevsky SB, Newman AB, Nevitt M, Rubin SM, Simonsick EM, Harris TB: Muscle mass, muscle strength, and muscle fat infiltration as predictors of incident mobility limitations in well-functioning older persons. J Gerontol A Bio/ Sci Med Sci 2005, 60(3):324-333.

9. Trombetti A, Reid KF, Hars M, Herrmann FR, Pasha E, Phillips EM, Fielding RA: Age-associated declines in muscle mass, strength, power, and physical performance: impact on fear of falling and quality of life. Osteoporos Int 2016, 27(2):463-471. 
10. The Whoqol Group: The World Health Organization Quality of Life Assessment (WHOQOL): development and general psychometric properties. Soc Sci Med 1998, 46(12):1569-1585.

11. Ware JE, Jr., Sherbourne CD: The MOS 36-item short-form health survey (SF-36). I. Conceptual framework and item selection. Med Care 1992, 30(6):473-483.

12. Bowling A, Stenner $P$ : Which measure of quality of life performs best in older age? A comparison of the OPQOL, CASP-19 and WHOQOL-OLD. J Epidemiol Community Health 2011, 65(3):273-280.

13. Motl RW, McAuley E: Physical activity, disability, and quality of life in older adults. Phys Med Rehabil Clin N Am 2010, 21(2):299-308.

14. Adhikari D, Rijal D: Factors affecting Health Seeking Behavior of Senior Citizens of Dharan. Journal of Nobel Medical College 2015, 4(7):57-63.

15. Karmacharya I, Ghimire S, Bhujel K, Dhauvadel AS, Adhikari S, Baral S, Shrestha N: Health Services Utilization among Older Adults in Pokhara Metropolitan City. 2019.

16. Ghimire S, Baral BK, Pokhrel BR, Pokhrel A, Acharya A, Amatya D, Amatya P, Mishra SR: Depression, malnutrition, and health-related quality of life among Nepali older patients. BMC Geriatr 2018, 18(1):191.

17. Dev MK, Paudel N, Joshi ND, Shah DN, Subba S: Impact of visual impairment on vision-specific quality of life among older adults living in nursing home. Curr Eye Res 2014, 39(3):232-238.

18. Yadav UN, Tamang MK, Thapa TB, Hosseinzadeh H, Harris MF, Yadav KK: Prevalence and determinants of frailty in the absence of disability among older population: a cross sectional study from rural communities in Nepal. BMC Geriatr 2019, 19(1):283.

19. Yadav UN, Tamang MK, Paudel G, Kafle B, Mehta S, Sekaran VC, Gruiskens JRH: The time has come to eliminate the gaps in the under-recognized burden of elder mistreatment: A community-based, cross-sectional study from rural eastern Nepal. PloS one 2018, 13(6):e0198410.

20. Bowling A: The psychometric properties of the older people's quality of life questionnaire, compared with the CASP-19 and the WHOQOL-OLD. Current Gerontology and Geriatrics Research 2009, 2009.

21. Bowling A, Stenner P: Which measure of quality of life performs best in older age? A comparison of the OPQOL, CASP-19 and WHOQOL-OLD. Journal of Epidemiology \& Community Health 2011, 65(3):273-280.

22. Kumar SG, Majumdar A, G P: Quality of Life (QOL) and Its Associated Factors Using WHOQOL-BREF Among Elderly in Urban Puducherry, India. J Clin Diagn Res 2014, 8(1):54-57.

23. Keshavarzi S, Ahmadi SM, Lankarani KB: The impact of depression and malnutrition on healthrelated quality of life among the elderly Iranians. Glob J Health Sci 2014, 7(3):161-170.

24. Ghimire S, Pradhananga P, Baral BK, Shrestha N: Factors Associated With Health-Related Quality of Life among Hypertensive Patients in Kathmandu, Nepal. Front Cardiovasc Med 2017, 4:69.

25. Kirkwood TB: A systematic look at an old problem. Nature 2008, 451(7179):644-647.

26. Thumboo J, Fong KY, Machin D, Chan SP, Soh CH, Leong KH, Feng PH, Thio S, Boey ML: Quality of life in an urban Asian population: the impact of ethnicity and socio-economic status. Soc Sci Med 
2003, 56(8):1761-1772.

27. Georgopoulou S, Wright AJ, Weinman J, Booth $\mathrm{H}$, Thornton $\mathrm{H}$, White P: The relationship between socioeconomic status, quality of life and healthcare access in COPD: A systematic review. In.: Eur Respiratory Soc; 2011.

28. Kim J-H, Park E-C: Impact of socioeconomic status and subjective social class on overall and healthrelated quality of life. BMC Public Health 2015, 15(1):783.

29. National Academies of Sciences E, Medicine: Health and Medicine Division, Board on Population Health and Public Health Practice \& Committee on Community-Based Solutions to Promote Health Equity in the United States. Communities in Action: Pathways to Health Equity Washington (DC): National Academies Press (US) 2017.

30. Kennedy BP, Kawachi I, Glass R, Prothrow-Stith D: Income distribution, socioeconomic status, and self rated health in the United States: multilevel analysis. BMJ 1998, 317(7163):917-921.

31. Anderson RT, Sorlie P, Backlund E, Johnson N, Kaplan GA: Mortality effects of community socioeconomic status. Epidemiology 1997, 8(1):42-47.

32. Marmot M, Shipley M, Brunner E, Hemingway $H$ : Relative contribution of early life and adult socioeconomic factors to adult morbidity in the Whitehall II study. J Epidemiol Community Health 2001, 55(5):301-307.

33. Sorensen K, Van den Broucke S, Fullam J, Doyle G, Pelikan J, Slonska Z, Brand H, Consortium Health Literacy Project E: Health literacy and public health: a systematic review and integration of definitions and models. BMC Public Health 2012, 12:80.

34. Marmot M: The influence of income on health: views of an epidemiologist. Health affairs 2002, 21(2):31-46.

35. Hanson MA, Cooper C, Aihie Sayer A, Eendebak RJ, Clough GF, Beard JR: Developmental aspects of a life course approach to healthy ageing. $J$ Physio/ 2016, 594(8):2147-2160.

36. McAuley E, Konopack JF, Motl RW, Morris KS, Doerksen SE, Rosengren KR: Physical activity and quality of life in older adults: influence of health status and self-efficacy. Ann Behav Med 2006, 31(1):99-103.

37. Phillips SM, Wojcicki TR, McAuley E: Physical activity and quality of life in older adults: an 18-month panel analysis. Qual Life Res 2013, 22(7):1647-1654.

38. Keysor JJ: Does late-life physical activity or exercise prevent or minimize disablement? A critical review of the scientific evidence. Am J Prev Med 2003, 25(3 Suppl 2):129-136.

39. Keysor JJ, Jette AM: Have we oversold the benefit of late-life exercise? J Gerontol A Biol Sci Med Sci 2001, 56(7):M412-423.

40. Pedisic Z, Shrestha N, Kovalchik S, Stamatakis E, Liangruenrom N, Grgic J, Titze S, Biddle SJ, Bauman $A E$, Oja $P$ : Is running associated with a lower risk of all-cause, cardiovascular and cancer mortality, and is the more the better? A systematic review and meta-analysis. Br J Sports Med 2019. 
41. Dahal D, Gurung Y, Acharya B, Hemchuri K, Swarnakar D: Situational analysis of dalits in Nepal. National Dalit Strategy Report: Part 2002, 1.

42. Yadav UN, Paudel G: Prevalence and associated factors of elder mistreatment: a cross sectional study from urban Nepal. Age Ageing 2016, 45(5):609-613.

43. Vitorino LM, Low G, Vianna LAC: Linking Spiritual and Religious Coping With the Quality of Life of Community-Dwelling Older Adults and Nursing Home Residents. Gerontol Geriatr Med 2016, 2:2333721416658140.

44. Koenig HG, Cohen HJ: The link between religion and health: Psychoneuroimmunology and the faith factor: Oxford University Press; 2002.

45. Kawano MM, Araujo IL, Castro MC, Matos MA: Assessment of quality of life in patients with knee osteoarthritis. Acta Ortop Bras 2015, 23(6):307-310.

46. Salaffi F, Carotti M, Stancati A, Grassi W: Health-related quality of life in older adults with symptomatic hip and knee osteoarthritis: a comparison with matched healthy controls. Aging Clin Exp Res 2005, 17(4):255-263.

47. van Dijk GM, Veenhof C, Schellevis F, Hulsmans H, Bakker JP, Arwert H, Dekker JH, Lankhorst GJ, Dekker J: Comorbidity, limitations in activities and pain in patients with osteoarthritis of the hip or knee. BMC Musculoskelet Disord 2008, 9:95.

48. Cao W, Guo C, Ping W, Tan Z, Guo Y, Zheng J: A Community-Based Study of Quality of Life and Depression among Older Adults. Int J Environ Res Public Health 2016, 13(7).

49. Shmuely $Y$, Baumgarten $M$, Rovner B, Berlin J: Predictors of improvement in health-related quality of life among elderly patients with depression. Int Psychogeriatr 2001, 13(1):63-73.

50. Hofmann SG, Curtiss J, Carpenter JK, Kind S: Effect of treatments for depression on quality of life: a meta-analysis. Cogn Behav Ther 2017, 46(4):265-286.

51. Wells KB, Stewart A, Hays RD, Burnam MA, Rogers W, Daniels M, Berry S, Greenfield S, Ware J: The functioning and well-being of depressed patients. Results from the Medical Outcomes Study. JAMA 1989, 262(7):914-919. 